\title{
Hemodynamic Effects of Pulmonary Arterial Infusion of Vasodilators in Newborn Lambs
}

\author{
MARJORIE E. TRIPP, ${ }^{(23)}$ WILLA H. DRUMMOND, MICHAEL A. HEYMANN, AND \\ ABRAHAM M. RUDOLPH \\ Cardiovascular Research Institute, University of California, San Francisco, California, USA
}

\section{Summary}

Pulmonary arterial infusion of prostaglandin $E_{1}$ (mean dose, 1 $\mu \mathrm{g} / \mathrm{kg} / \mathrm{min}$ ) in term neonatal lambs ventilated with room air resulted in a slight fall in pulmonary arterial pressure $(P<0.05)$. Infusion during ventilation with low oxygen mixtures resulted in a parallel fall in pulmonary and arterial pressures and resistances. Intrapulmonary infusion of acetylcholine (mean dose, $3.9 \mu \mathrm{g} / \mathrm{kg} /$ min) in lambs during ventilation with room air caused a slight fall in mean systemic arterial pressure and systemic vascular resistance. When repeated with low oxygen ventilation, infusion of acetylcholine caused a parallel fall in both pulmonary and systemic arterial pressures and resistances. Infusion of tolazoline at a mean dose of $0.21 \mathrm{mg} / \mathrm{kg} / \mathrm{min}$ did not change pulmonary or systemic arterial pressures or resistances when the lambs were ventilated with room air or with hypoxic gas mixtures although individual animals experienced marked falls in systemic arterial pressure.

Pulmonary arterial infusion of each of the three vasodilators during hypoxic ventilation resulted in potentially adverse bemodynamic effects. This occurred despite prior ductal ligation, implying that doses effective for pulmonary vasodilatation may exceed doses without systemic effects particularly in the acute hypoxic state.

\section{Speculation}

Vasodilators specific for pulmonary vascular smooth muscle have not been developed. Nonspecific vasodilators cause relaxation of pulmonary and systemic vascular smooth muscle which is most marked during hypoxemia. Increased pulmonary blood flow will result from vasodilatation only if the ratio of pulmonary to systemic vascular resistance decreases or if cardiac output rises. Parallel changes in pulmonary and systemic resistance with vasodilators during hypoxic pulmonary hypertension with right to left shunting may prevent clinically useful improvement in oxygenation.

Neonatal pulmonary vascular smooth muscle constricts in response to decreased oxygen tension (11) and increased hydrogen ion concentration (18). When pulmonary vascular resistance exceeds systemic vascular resistance, hypoxia, and acidosis may be exacerbated by right-to-left shunting across the foramen ovale and ductus arteriosus. Constriction of the pulmonary vascular bed is considered important in the pathogenesis of respiratory distress syndrome (2), meconium aspiration syndrome (7), and in persistent pulmonary hypertension of the newborn also referred to as persistent fetal circulation (5).

Attempts have been made to relieve pulmonary vasoconstriction in neonates by increasing alveolar ventilation and by administering pharmacologic agents which relax vascular smooth muscle. These pharmacologic agents are not selective pulmonary vasodilators and are known to affect systemic vasculature. Their use in infants with hypoxic stress, in whom systemic as well as pulmonary vasoconstriction occurs, requires evaluation because of potential adverse systemic effects. We studied three agents reported to have prominent vasodilator effects: acetylcholine, tolazoline, and prostaglandin $E_{1}$. Studies were conducted acutely in lambs delivered by cesarean section. Effects of the drugs were examined while the lambs were being ventilated with room air and with low oxygen mixtures.

\section{MATERIALS AND METHODS}

Fourteen lambs of gestational ages of 139 to 144 days (term, 150 days), weighing 2.9 to $5.2 \mathrm{~kg}$ were instrumented in utero. One lamb, delivered spontaneously, was studied within $12 \mathrm{hr}$ of birth. Pregnant ewes were given low spinal analgesia with $2 \mathrm{ml}$ of $1 \%$ tetracaine hydrochloride (Pontocaine). The uterus was exposed through a vertical midline abdominal incision, and the fetal hindlimb was extracted through a small uterine incision. Local anesthesia was achieved with $0.5 \%$ lidocaine hydrochloride (Xylocaine). Polyvinyl catheters (0.030 inch inside diameter; 0.048 inch outside diameter) were advanced into the descending aorta and inferior vena cava through a saphenous artery and vein. The fetal leg was returned to the uterus. The head was then exposed through a separate incision; the mouth and nose were immediately covered with a saline-filled glove to avoid expansion of the lungs with air. Through a small right lateral incision in the neck, the trachea was cannulated with a clamped saline-filled tube. Polyvinyl catheters were passed into the ascending aorta and the superior vena cava via the right carotid artery and jugular vein. Care was taken to avoid interference with the cervical vagus trunk during dissection.

The forelimb of the fetus was then delivered and, with local anesthesia, the fetal chest was opened in the fourth left intercostal space. The pulmonary trunk was exposed, the ductus arteriosus was mobilized, and a suture was placed around it. Care was taken to avoid manipulation of the vagal and sympathetic nerves in this area. An electromagnetic flow transducer was placed around the pulmonary trunk. Through a purse string suture in the pulmonary artery, a small stab wound was made and a polyvinyl catheter ( 0.030 inch inside diameter; 0.048 inch outside diameter) was inserted into the pulmonary artery. The ductus arteriosus was ligated, and positive pressure ventilation was begun with a Harvard respiratory pump using a tidal volume of $10 \mathrm{ml} / \mathrm{kg}$, and a rate of $30 / \mathrm{min}$. An end expiratory pressure of $2 \mathrm{~cm}$ of water was maintained by inserting the expiratory tube of the pump $2 \mathrm{~cm}$ below a fluid level. Adjustments were made as necessary to maintain desired arterial blood gases. The chest was then closed, and the umbilical cord was clamped. The lamb was delivered from the uterus through the incision and placed on a warming pad. Rectal temperature was measured with a thermister probe and was maintained at $39^{\circ} \mathrm{C}$ with the use of overhead radiant lamps. Lambs were loosely restrained, but in all instances succinylcholine chloride was administered every $30 \mathrm{~min}$ to maintain a stable mechanical ventilation. In most studies, a catheter was inserted into an umbilical artery for continuous measurement of oxygen tension in descending aortic blood (G. D. Searle and Co.).

We continuously recorded mean pulmonary arterial and aortic 
pressures, phasic and mean pulmonary blood flow, heart rate, respiratory rate, and intratracheal pressure. Pressures were measured using Statham P23Db transducers. Pulmonary blood flow was measured using an electromagnetic flow transducer connected to a Statham SP2202 flowmeter (12). Pressures, flows, and rates were recorded on a Beckman Dynograph multichannel recorder. The lambs were first ventilated with room air and then with gas mixtures containing 9 to $15 \%$ oxygen in nitrogen with $1 \%$ carbon dioxide. Control measurements were made both during normoxia and hypoxia for a 10-min period before infusion of drugs.

Drugs were infused through a Sorenson adapter into the pulmonary arterial catheter, allowing continuous monitoring of pulmonary arterial pressure during infusion. Drug infusion rates were determined in each lamb by a titration to find the lowest dose causing changes in measured hemodynamic parameters in the control state. This dose was again used in the hypoxic state. Because instrumentation was performed in utero, accurate weights could not be obtained until after the experiments completion. Doses therefore varied for individual lambs on a per kilogram basis.

Carotid arterial blood was withdrawn from the catheter for measurement of $\mathrm{PO}_{2}, \mathrm{PCO}_{2}$, and $\mathrm{pH}$ before, during, and after drug infusions. Measurements were made using a Radiometer blood gas analyzer. A minimum of $\mathbf{3 0 ~ m i n ~ a f t e r ~ r e t u r n ~ o f ~ p r e s s u r e s ~}$ and flows to baseline was allowed between drug infusions. The sequence of study of normoxia and hypoxia and of the three drugs was varied in different animals.

Vascular resistance was calculated by dividing the mean pressure difference across the vascular bed by the pulmonary blood flow. Although the ductus arteriosus was ligated in all animals, right-to-left shunting across the foramen ovale could not be excluded. Therefore, some underestimate of systemic blood flow and overestimate of systemic vascular resistance may have occurred. Measurement of mean left atrial pressure in three of the reported lambs and in several lambs not in the study yielded values of 4 to $6 \mathrm{~mm} \mathrm{Hg}$ when the lambs were ventilated with an end tidal pressure of $2 \mathrm{~cm}$ water. These values were not different during ventilation with low oxygen gas mixtures. In the remaining 11 lambs, left atrial lines were not placed, and the mean pressure difference across the pulmonary vascular bed was calculated using an assumed left atrial pressure of $5 \mathrm{~mm} \mathrm{Hg}$.

Statistical analyses were done by Student's paired $t$ testing. Values were considered significant when $P$ was less than 0.05 .

\section{RESULTS}

Arterial blood gases for the control periods before drug infusion are reported in Table 1 . Ventilation with low oxygen gas mixtures resulted in a marked fall in arterial oxygen tension in all three experimental groups. Arterial $\mathrm{pH}$ and $\mathrm{PCO}_{2}$ were not significantly altered. The mild respiratory alkalosis of the acetylcholine group during room air and hypoxic ventilation and of the prostaglandin group during hypoxic ventilation only did not attain statistical significance.

\section{PROSTAGLANDIN $E_{1}$ INFUSION}

Infusion of prostaglandin $E_{1}$ in a mean dose of $1.0 \mu \mathrm{g} / \mathrm{kg} / \mathrm{min}$ caused a fall in pulmonary arterial mean pressure from $38 \pm 3$ to
$29 \pm 3 \mathrm{~mm} \mathrm{Hg}$ during the normoxic period $(P<0.05$; Fig. 1). Mean systemic arterial pressure also fell during the infusion, but $P$ was not significant. Changes in pulmonary blood flow (Fig. 2) and pulmonary and systemic vascular resistance were not significant. The ratio of pulmonary to systemic vascular resistance did not change.

During hypoxia the pulmonary arterial pressure increased from $38 \pm 3$ to $48 \pm 5 \mathrm{~mm} \mathrm{Hg}(P<0.05)$, and mean systemic arterial pressure fell from $71 \pm 8$ to $54 \pm 6 \mathrm{~mm} \mathrm{Hg}(P<0.05)$. A fall in pulmonary blood flow from $143 \pm 12 \mathrm{ml} /$ minute $/ \mathrm{kg}$ to $120 \pm 13$ $\mathrm{ml} / \mathrm{min} / \mathrm{kg}$ did not attain statistical significance. Pulmonary vascular resistance increased from a control level of $0.25 \pm 0.06$ to $0.51 \pm 0.18$ units during hypoxia $(P<0.05)$. Systemic vascular resistance did not change. There was marked increase in the ratio of pulmonary to systemic vascular resistance from $0.53 \pm .05$ to $0.98 \pm .11(P<0.05)$. Prostaglandin $E_{1}$ infusion during hypoxia resulted in a decrease both in pulmonary and systemic arterial mean pressures (both $<0.05$ ). The pulmonary and systemic vascular resistances also fell $(P<0.05)$, but the ratio of pulmonary to systemic vascular resistance, $0.94 \pm 0.11$, did not change as compared with that during hypoxia alone.

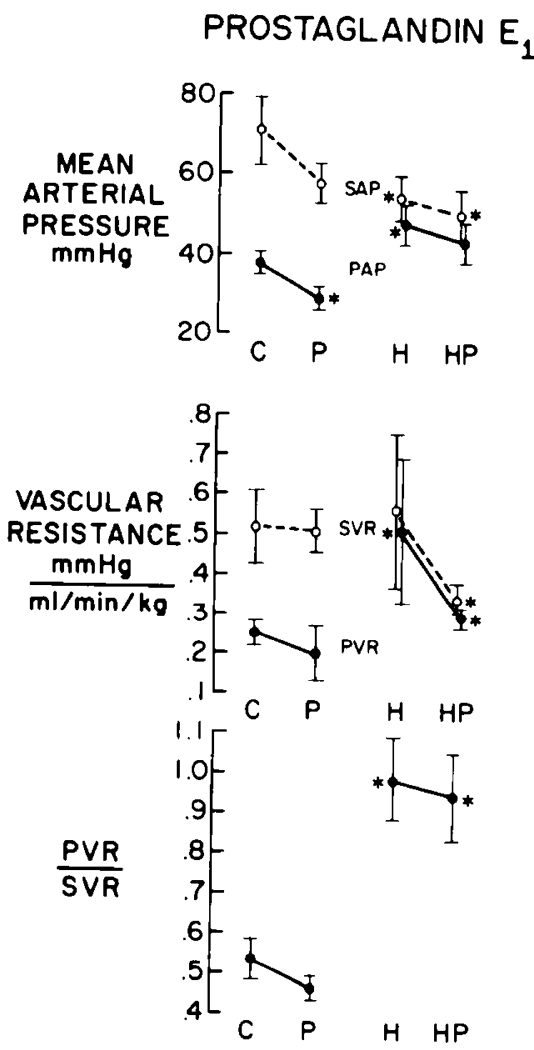

Fig. 1. Hemodynamic effects of prostaglandin $E_{1}$ infusion (mean dose, $1.0 \mu \mathrm{g} / \mathrm{kg} / \mathrm{min}$ ) into the main pulmonary artery of neonatal lambs. $O$, systemic data $\pm 1 \mathrm{SD} ;$, pulmonary data \pm I S.D.: *, $P<0.05$; C, control; $P, P G E_{1}$, infusion; $H$, hypoxic ventilation; $H P, P E_{1}$ infusion during hypoxic ventilation; SAP, PAP, systemic, pulmonary arterial pressure; SVR, PVR, systemic, pulmonary vascular resistance.

Table 1. Control arterial blood gases before drug infusion

\begin{tabular}{|c|c|c|c|c|c|c|}
\hline \multirow[b]{2}{*}{ Group } & \multicolumn{3}{|c|}{ Room Air } & \multicolumn{3}{|c|}{ Low Oxygen } \\
\hline & $\mathrm{pH}$ & $\mathrm{PO}_{2}$ & $\mathrm{PCO}_{2}$ & $\mathrm{pH}$ & $\mathrm{PO}_{2}$ & $\mathrm{PCO}_{2}$ \\
\hline $\mathrm{PGE}_{1}{ }^{\prime}$ & $7.39 \pm 0.03^{2}$ & $72 \pm 11$ & $30 \pm 3$ & $7.43 \pm 0.04$ & $22 \pm 3^{3}$ & $23 \pm 4$ \\
\hline $\mathrm{ACh}$ & $7.46 \pm 0.04$ & $72 \pm 3$ & $23 \pm 3$ & $7.41 \pm 0.03$ & $16 \pm 1^{3}$ & $27 \pm 4$ \\
\hline Tol & $7.35 \pm 0.03$ & $68 \pm 2$ & $29 \pm 3$ & $7.34 \pm 0.04$ & $17 \pm 1^{3}$ & $28 \pm 2$ \\
\hline
\end{tabular}

${ }^{1} \mathrm{PGE}_{1}$, Prostaglandin $\mathrm{E}_{1}$; ACh, Acetylcholine; Tol, Tolazoline.

${ }^{2}$ Mean \pm S.D.

${ }^{3} P<0.01$ comparing low oxygen ventilation with room air. 


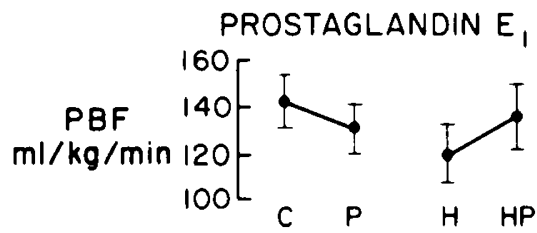

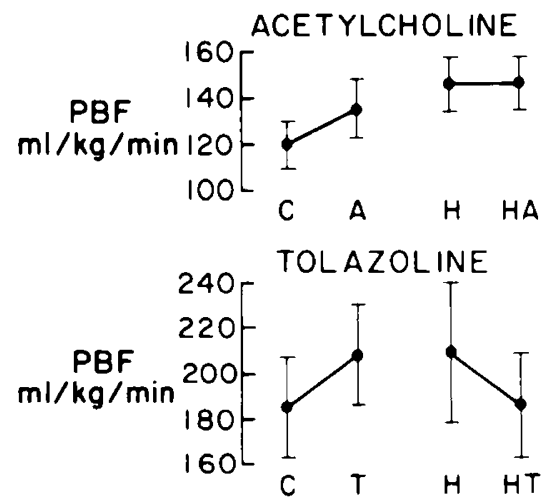

Fig. 2. Changes in pulmonary blood flow during vasodilator infusion into the pulmonary artery of neonatal lambs. PBF, pulmonary blood flow: $C$, control; $H$, hypoxic ventilation; $P$, prostaglandin $E_{1} ; A$, acetylcholine: T, tolazoline. $P$, N.S

\section{ACETYLCHOLINE INFUSION}

During the normoxic period, infusion of acetylcholine at a mean dose of $3.9 \mu \mathrm{g} / \mathrm{kg} / \mathrm{min}$ resulted in no significant change in mean pulmonary arterial pressure ( $37 \pm 4$ to $34 \pm 3 \mathrm{~mm} \mathrm{Hg}$ ) (Fig. 3). However, systemic arterial pressure fell slightly, $(78 \pm 4$ to $69 \pm$ $5 \mathrm{~mm} \mathrm{Hg} ; P<0.05$ ). Pulmonary blood flow tended to increase, but there was no significant change (Fig. 2). The pulmonary vascular resistance did not change, but there was a fall in systemic vascular resistance, $0.63 \pm 0.06$ to $0.48 \pm 0.04(P<0.05)$. The ratio of pulmonary to systemic vascular resistance did not change.

Induction of hypoxia before acetylcholine infusion again resulted in significant increases in pulmonary arterial pressure and pulmonary vascular resistance, as well as a significant decrease in systemic arterial mean pressure and systemic vascular resistance; there was also a significant increase in pulmonary to systemic vascular resistance ratios. Pulmonary blood flow, however, did not change significantly. During hypoxia, infusion of acetylcholine resulted in a marked decrease in both pulmonary and systemic mean arterial pressures. Pulmonary blood flow tended to increase slightly $(P, N$.S. $)$. The pulmonary and systemic vascular resistances both fell $(P<0.05)$. The pulmonary to systemic vascular resistance ratio was not significantly changed from that seen with hypoxia alone.

\section{TOLAZOLINE INFUSION}

Tolazoline hydrochloride, when infused at rates of $0.21 \mathrm{mg} / \mathrm{kg} /$ min, did not change systemic or pulmonary or arterial pressure either during the normoxic or hypoxic periods (Fig. 4). Pulmonary blood flow showed no significant change (Fig. 2). Neither pulmonary nor systemic vascular resistance were altered by tolazoline infusion during ventilation with room air. The pulmonary vascular resistance that was increased by hypoxia was not reduced by tolazoline infusion. When tolazoline was infused, pulmonary to systemic vascular resistance ratios actually increased during normoxia and increased further during hypoxia.

Although the average systemic vascular resistance in the six animals that received tolazoline infusion did not drop significantly, there were dramatic changes in systemic arterial pressure in some of the lambs. In those animals, the progressive fall in pulmonary blood flow associated with the tolazoline continued until either the infusion was discontinued or oxygen was administered.

\section{COMBINED EXPERIENCE}

When drug groups were compared using single-factor analysis of variance, no significant differences could be found. In each drug group, pulmonary arterial pressures rose, and systemic arterial pressures fell with hypoxia. Drug infusion during hypoxia resulted in a fall in both pulmonary and systemic arterial pressures. However, in all groups, the ratio of pulmonary to systemic vascular resistance was determined by hypoxia alone.

\section{DISCUSSION}

Prostaglandin $E_{1}$, acetylcholine, and tolazoline hydrochloride have all been reported to have pulmonary vasodilator effects on constricted pulmonary vessels. Prostaglandin $E_{1}$ decreased pulmonary vascular resistance when infused into perfused lung lobes of fetal lambs or newborn goats $(1,21)$. A decrease in pulmonary vascular resistance with an increase in pulmonary blood flow in chronically instrumented fetal lambs in utero has also been reported (20). Cassin et al. (1) and Tyler et al. (21) did not observe a decrease in systemic arterial pressure when they infused prostaglandin $E_{j}$ into the pulmonary arterial circulation. It is difficult to explain the decrease in systemic arterial pressure that we observed because it has been reported that prostaglandins of the E-series are rapidly metabolized in the pulmonary vascular bed (6). Our findings suggest that the infusion rate of prostaglandin

\section{ACETYLCHOLINE}
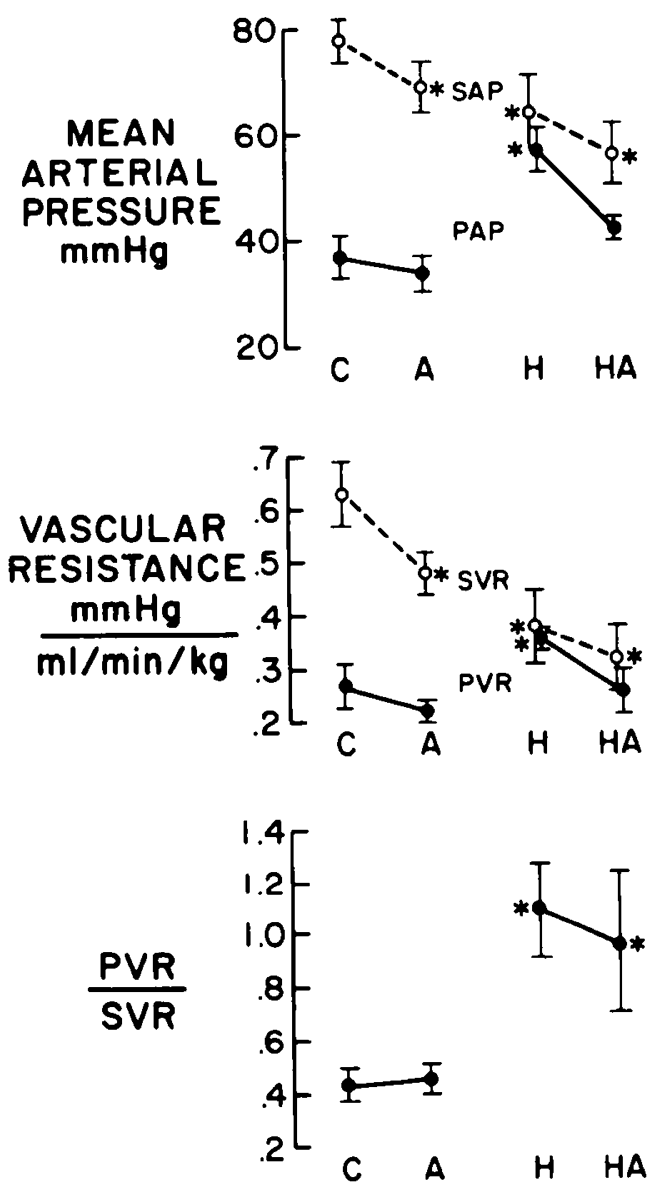

Fig. 3. Hemodynamic effects of acetylcholine infusion (mean dose, 3.9 $\mu \mathrm{g} / \mathrm{kg} / \mathrm{min}$ ) into the main pulmonary artery of neonatal lambs. $O$, systemic data \pm 1 S.D.; $*, P<0.05 ; 0$, pulmonary data \pm 1 S.D. C. control; A, ACh infusion; H, hypoxic ventilation; HA, acetylcholine infusion during hypoxic ventilation; SAP, PAP, systemic, pulmonary arterial pressure; SVR, PVR, systemic, pulmonary vascular resistance. 


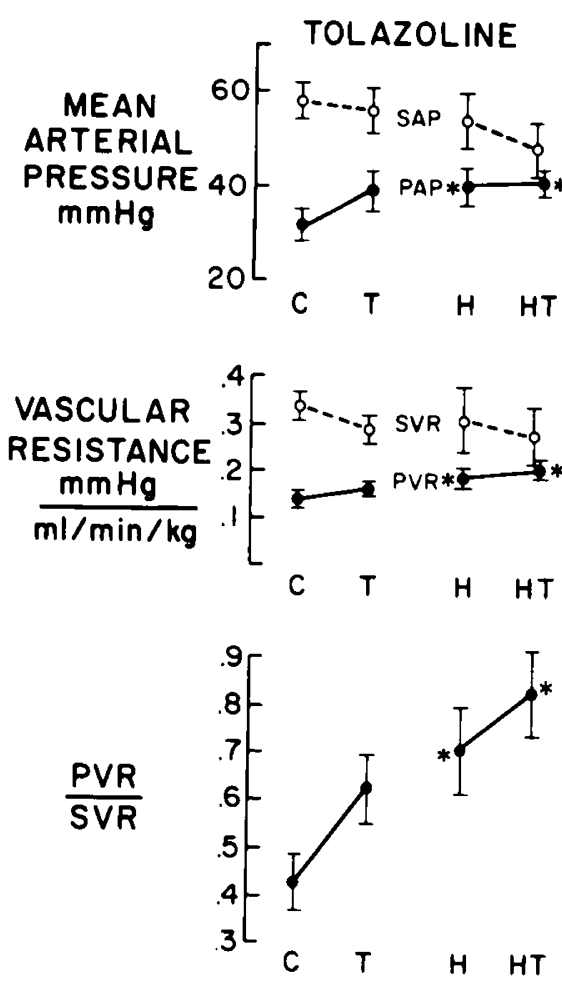

Fig. 4. Hemodynamic effects of tolazoline hydrochloride (tol) infusion (mean dose, $0.21 \mathrm{mg} / \mathrm{kg} / \mathrm{min}$ ) into the main pulmonary artery of neonatal lambs. $O$, systemic data \pm 1 S.D. $\bullet$, pulmonary data \pm S.D. ${ }^{*}, P<0.05$. $C$, control, $T$, tolazoline infusion, $H$, hypoxic ventilation, $H T$, tolazoline infusion during hypoxic ventilation. SAP, PAP, systemic, pulmonary arterial pressure. SVR, PVR, systemic, pulmonary vascular resistance.

required to produce an effect on the pulmonary circulation exceeds the rate of catabolism in the neonatal lung allowing the drug to pass through into the systemic circulation. Because the systemic vascular bed dilated during prostaglandin $E_{1}$ infusion, the concentration of that drug required to affect the systemic vasculature is lower than that which will dilate the pulmonary circulation.

The ability of the lung to metabolize prostaglandins of the Eseries varies in fetal and newborn lambs as compared with adult animals (15). This may account for the marked systemic effects associated with infusion into the pulmonary circulation in the newborn animal. The difference in our findings as compared with those of Cassin's laboratory could be related to the fact that their animals were anesthetized whereas our animals were not.

Acetylcholine is a potent vasodilator in the systemic circulation. It has been reported to have variable effects on the pulmonary circulation, but it seems that its effect is dependent on the state of constriction of the pulmonary vessels (8). In newborn puppies, acetylcholine produced a small increase in right ventricular or pulmonary arterial pressure when animals were breathing air, but caused a decrease in these pressures during hypoxia (16). Similarly, acetylcholine produced vasodilatation of serotonin-constricted vessels in adult dogs but constricted normal vessels (17). Acetylcholine has also been shown to dilate fetal pulmonary vessels (4, 14). It has been used clinically to produce pulmonary vasodilatation in hyaline membrane disease (2) and in newborn infants with congenital diaphragmatic hernia (3). In our studies in newborn lambs, acetylcholine produced a mild fall in pulmonary vascular resistance during normoxia while markedly decreasing systemic vascular resistance. Similarly, during hypoxia, infusion of acetylcholine caused a relatively small fall in pulmonary vascular resistance, but a marked decrease in systemic vascular resistance. Acetylcholine is rapidly inactivated in blood by the action of cholinesterases. Because the drug was infused directly into the pulmonary artery, the concentration that reached the pulmonary vessels must have been considerably higher than that reaching the systemic circulation, indicating that the systemic vasculature responded to much lower concentrations than did the pulmonary circulation.

Tolazoline produces competitive alpha-adrenergic blockade in both the pulmonary and systemic circulations (13). It is also felt by some investigators to have direct relaxant action on vascular smooth muscle (10).

Tolazoline hydrochloride has been reported to be an effective pulmonary vasodilator in adult animals subjected to hypoxia and has been used to decrease pulmonary arterial pressure in patients with primary pulmonary hypertension (10). In patients with congenital heart disease, tolazoline dilates the pulmonary circulation in some children with pulmonary arterial hypertension associated with ventricular septal defects. Pulmonary vasodilatation occurs in children in whom pulmonary vascular resistance is moderately increased. It was suggested that a response occurred in the presence of a thick medial muscular layer with vasoconstriction in the pulmonary circulation; no response occurred in children in whom pulmonary vascular resistance was very high and in whom the pulmonary vascular changes were thought to be due to intimal proliferation and luminal obstruction (22). Recently, tolazoline has been used in newborn infants to dilate the pulmonary circulation in settings of presumed persistence of a high pulmonary vascular resistance (9).

In view of the effectiveness of tolazoline in several clinical studies, we were surprised that we could not demonstrate a vasodilator effect in newborn lambs either during normoxia or with hypoxia. It is possible that the lack of response could be due to a species difference in sheep, although this does not seem to explain all of our findings. In some lambs, the drug produced a very marked fall in systemic vascular resistance, indicating that it had vasodilator activity in the lamb. The differences in response could be related to differences in mechanisms responsible for pulmonary vasoconstriction. This is suggested by recent observations, in which the use of tolazoline resulted in quite variable responses, whereas some infants did not show evidence of a decrease in pulmonary vascular resistance (19). Wide individual difference in response could make statistical analysis difficult in small series.

These results emphasize the lack of specificity of available vasodilators and underscore the need for caution in their clinical use. Despite direct intrapulmonary infusion after ductal ligation, all three drugs caused a fall in systemic arterial pressure and systemic vascular resistance in hypoxic animals. In no case was pulmonary blood flow significantly improved. Direct support of oxygenation with mechanical ventilation, correction of acidosis, and support of cardiac output with inotropic agents remain the treatment of choice in neonatal persistence of elevated pulmonary vascular resistance. These data suggest that the use of vasodilators for pulmonary vasoconstriction be pursued only when systemic pressures can be closely monitored and arterial gases frequently determined. If rapid clinical improvement cannot be demonstrated, vasodilators should be discontinued because adverse systemic effects may occur, particularly with prolonged use.

\section{REFERENCES AND NOTES}

1. Cassin, S., Tyler, T., and Wallis, R.: The effects of prostaglandin E-I on fetal pulmonary vascular resistance. Proc. Soc. Exp. Biol. Med., 148: 584 (1975)

2. Chu. J., Clements, J., Colten, E., Klaus, M., Sweet, A., Thomas M., Tooley, W., and Wright. K.: The pulmonary hypoperfusion syndrome. Pediatrics, 35: 733 (1965).

3. Collins, D. L., Marks, L., Edwards, D., Kirkpatrick, S. E., and Nyhan, W. L. Specialty conference: management of infants with diaphragmatic hernia. West J. Med., 127: 479 (1977)

4. Dawes, G. S., and Mott. J. C.: The vascular tone of the foetal lung. J. Physiol. (Lond.). 164: 465 (1962)

5. Drummond, W. H., Peckham, G. J., and Fox, W. W.: The clinical profile of the newborn with persistent pulmonary hypertension. Clin. Pediatr., I6: 335 (1977).

6. Ferreira. S. H., and Vane, J. R.: Prostaglandins: their disappearance from and release into the circulation. Nature (Lond.), 216: 868 (1967).

7. Fox, W.. Getwitz. M. H., Dinwiddie, R., Drummond, W. H., and Peckham, G $J .:$ The occurrence of pulmonary hypertension in the perinatal aspiration syndrome. Pediatrics, 59: 205 (1977).

8. Fritts, H. W.. Harris, P., Clauss, R. H., Odell, J. E., and Cournan. C. A.: The 
effect of acetylcholine on the human pulmonary circulation under normal and hypoxic conditions. J. Clin. Invest., 37: 99 (1958).

9. Goetzman, B. W. Sunshine, P. Johnson, J. D. Wennberg, R. P., Hackel, A Merten, D. F., Bartoletti, A. L., and Silverman, N. H.: Neonatal hypoxia and pulmonary vasospasm: response to tolazoline. J. Pediatr., 89: 617 (1976).

10. Grover, R. V., Reeves, J. T., and Blount, S. G.: Tolazoline hydrochloride: an effective pulmonary vasodilator. Am. Heart J., 61: 5 (1961)

1. Hyman, A. L., and Kadowitz, P. J.: Effects of alveolar and perfusion hypoxia on pulmonary vascular resistance in the lamb. Am. J. Physiol., 228: 397 (1975).

12. Klopfenstein, H. S., and Rudolph, A. M.: Postnatal changes in the circulation and responses to volume loading in sheep. Circ. Res., 42: 839 (1978).

13. Nickerson, M.: The pharmacology of advenergic blockade. Pharmacol. Rev., $I$ 27 (1949).

14. Nuwayhid, B.: Systemic and pulmonary hemodynamic responses to adrenergic and cholinergic agonists during fetal development. Biol. Neonate, 26: 30 (1975).

15. Pace-Asciak, C. R.: Prostaglandin biosynthesis and catabolism in several organ of developing fetal and neonatal animals. In: F. Coceani, P. M. Olley: Advances in Prostaglandin and Thromboxane Research. Vol. 4, pp. 45-59 (Raven Press, New York. 1978).

16. Rudolph, A. M.. Auld, P. A. M., Golinko, R. J., and Paul, M. H.: Pulmonary vascular adjustments in the neonatal period. Pediatrics, 28: 28 (1961).

17. Rudolph, A. M., Kurland, M. D., Auld, P. A. M., and Paul. M. H.: Effects of vasodilator drugs on normal and serotonin-constricted pulmonary vessels of the dog. Am. J. Physiol., 197: 617 (1959).

Copyright $\odot 1980$ International Pediatric Research Foundation. Inc $0031-3998 / 80 / 1412-1311 \$ 02.00 / 0$
18. Rudolph, A. M., and Yuan, S.: Response of the pulmonary vasculature to hypoxia and hydrogen ion changes. J. Clin. Invest., 45: 399 (1966)

19. Stevenson, D. K Kasting, D. S. Darnall, R. A., Aviagno, R. L., Johnson, J. D. Malachowski, N., Beets, C. L., and Sunshine, P.: Refractory hypoxemia associated with neonatal pulmonary disease: the use and limitations of tolazoline. J. Pediatr., 95: 595 (1979).

20. Tripp, M. E., Heymann, M. A., and Rudolph, A. M.: Hemodynamic effects of prostaglandin $E_{1}$ on lambs in utero. Advances in Prostaglandin and Thromboxane Research, Vol. 4, In: F. Coceani, P. M. Olley: p. 221-229 (Raven Press. New York, 1978)

21. Tyler, T., Leffler, C.. Wallis, R., and Cassin, S.: Effects of prostaglandins of the E-series on pulmonary and systemic circulations of newborn goats during normoxia and hypoxia. Prostaglandins, 10: 963 (1975).

22. Vogel, J. H. K., Grover, R. F., and Blount, S. G.: Pathophysiologic correlations in patients with ventricular septal defect and increased pulmonary vascular resistance. Am. J. Cardiol., 19: 154 (1967).

23. Requests for reprints should be addressed to: Marjorie E. Tripp, M.D., Department of Pediatrics, H4/470 University Hospital, 600 Highland Ave., Madison. WI 53792.

24. This research was supported by Program Project Grant HL-06285 from the National Heart, Lung and Blood Institute. Dr. Tripp was supported by NIH post doctoral research fellowship, HL-05207. Dr. Drummond received support from NIH grant, HD-10682.

25. Received for publication January 16, 1980.

26. Accepted for publication March 15, 1980. 